\title{
Seroprevalence of hepatitis B surface antigen (HBsAg) in Bo, Sierra Leone, 2012-2013
}

\author{
Rashid Ansumana ${ }^{1,2^{*}}$, Donald F. Dariano 3rd³, Kathryn H. Jacobsen ${ }^{4}$, Tomasz A. Leski ${ }^{3}$, Joseph M. Lamin ${ }^{1}$, \\ Joseph Lahai ${ }^{1}$, Umaru Bangura ${ }^{1}$, Alfred S. Bockarie ${ }^{1,2}$, Chris R. Taitt ${ }^{3}$, Chadwick Yasuda ${ }^{3}$, Moses J. Bockarie ${ }^{5}$ \\ and David A. Stenger ${ }^{3}$
}

\begin{abstract}
Objective: The aim of this study was to determine the prevalence of hepatitis B surface antigen (HBsAg) among febrile individuals tested at Mercy Hospital Research Laboratory (MHRL) in Bo, Sierra Leone.

Results: A total of 860 febrile individuals ages 5 years and older were tested by MHRL between July 2012 and June 2013 with a Standard Diagnostics Bioline HBsAg rapid diagnostic test. The overall HBsAg prevalence rate was 13.7\%, including a rate of $15.5 \%$ among males and $12.6 \%$ among females. The HBsAg rate did not differ by child or adult age group ( $p>0.5)$. The prevalence rate in Bo was similar to the 11-15\% HBsAg prevalence rates reported in the past decade from other studies across West Africa. Scaling up the infant hepatitis B vaccination program in Sierra Leone will be important for reducing the future burden of disease and premature death attributable to chronic viral hepatitis B disease.
\end{abstract}

Keywords: Seroprevalence, Hepatitis B, HBsAg, Bo, Sierra Leone

\section{Introduction}

Viral hepatitis is a major cause of morbidity and mortality worldwide, with hepatitis B virus (HBV) the agent responsible for the greatest number of viral hepatitis deaths and disability-adjusted life years (DALYs) lost annually [1]. Viral hepatitis has recently gained new recognition as a public health priority globally and in highburden regions like West Africa [2]. In 2010, the World Health Assembly adopted a resolution calling for more action to prevent and control chronic viral hepatitis infection in countries bearing a high burden from these diseases [3]. In 2012, the World Health Organization (WHO) released a global action plan for viral hepatitis prevention and control [4]. An updated health sector strategy for viral hepatitis was released by WHO in 2016 [5]. Additionally, the Sustainable Development Goals (SDGs) for 2016-2030 include a target for combatting viral hepatitis as part of broader efforts by the United Nations and its partner agencies and organizations to end

\footnotetext{
*Correspondence: rashidansumana@gmail.com

${ }^{1}$ Mercy Hospital Research Laboratory, Kulanda Town, Bo, Sierra Leone

Full list of author information is available at the end of the article
}

poverty, promote human and environmental health, and foster peace and prosperity [6]. Progress toward achieving this SDG target will be monitored with an indicator of hepatitis $B$ incidence, the number of new hepatitis $B$ infections per 100,000 people per year [6].

The rates of deaths and DALYs attributable to hepatitis $B$ in West Africa are among the highest found in any world region [1, 7-9]. HBV is spread through parenteral transmission (that is, through contact with blood or other body fluids via needles, open wounds, or other portals of entry) as well as through sexual contact and perinatal (mother-to-child) transmission during delivery. About $90 \%$ of infected infants and some older children and adults who contract HBV fail to clear the virus and develop a chronic infection [10]. People with chronic HBV have an elevated risk of cirrhosis, hepatocellular carcinoma (a type of liver cancer), and other liver diseases. These sequelae increase the risk of premature death in adulthood. While a hepatitis B vaccine is available, it has not been adopted for use in all countries and most adults worldwide were born before hepatitis B 
vaccination was part of any routine childhood vaccination schedules [11].

There is a need for up-to-date epidemiological data about viral hepatitis so that progress toward achieving the SDG target can be monitored. A lack of recent serosurvey data from many low-income countries means that most current estimates of the burden from viral hepatitis in lower-income areas have been generated by mathematical models like the ones from the Global Burden of Disease (GBD) project rather than being based on field data [1]. New serosurvey data will be valuable for understanding the epidemiological profiles of studied populations. They will also improve the accuracy of GBD estimates in the study countries and their neighbors.

There are few recent studies of viral hepatitis from Sierra Leone. Serosurveys conducted in Freetown in the early 2000s reported hepatitis B prevalence rates of $22 \%$ among 198 adults and 6\% among 302 pregnant women $[12,13]$. A study of 66 young children in the 1990s found an $18 \%$ prevalence of hepatitis B [14], and a study of 179 pregnant women in 1995-1996 found an 11\% prevalence rate [15]. More recently, a small study of 308 patients of Bo Government Hospital found a $21.4 \%$ hepatitis B seropositivity rate [16]. These studies suggest a high burden from hepatitis B in Sierra Leone, but that needs to be confirmed with new and more extensive data. The goal of this study was to determine the current prevalence of hepatitis B infection in Bo, Sierra Leone.

\section{Main text Methods}

Mercy Hospital (MH) and the Hospital Research Laboratory (MHRL) are located in Bo, Sierra Leone. Between July 2012 and June 2013, MHRL conducted a research study examining the etiology of febrile illnesses among residents of Bo. To be eligible for this study, individuals had to live in Bo, be at least 5 years old, consent to participation (or, for minor children, have a parent or legal guardian provide consent), and have a fever that they reported began no more than $72 \mathrm{~h}$ (3 days) before they arrived at MHRL to seek testing. None of the participants had received hepatitis $B$ vaccination. The research protocol was approved by Njala University (Bo, Sierra Leone), George Mason University (Fairfax, Virginia, USA), the U.S. Naval Research Laboratory (Washington, DC, USA), the Liverpool School of Tropical Medicine (Liverpool, UK), and the Sierra Leone Ethics and Scientific Review Committee.

Hepatitis B surface antigen ( $\mathrm{HBsAg}$ ) is the standard test used to diagnose acute or chronic infection with HBV. HBsAg kits from SD Bioline (Standard Diagnostics, Seoul, Republic of Korea) were used for these tests. The SD Bioline HBsAg rapid diagnostic test (RDT) is reported to have a $98 \%$ sensitivity and a $99 \%$ specificity [17]. Blood samples were collected using a BD Vacutainer Safety-Lok ${ }^{\text {TM }}$ blood collection set with a pre-attached holder (Beckton, Dickinson, and Company, Franklin Lakes, New Jersey, USA). The collected blood was aliquoted into BD Vacutainer tubes (purpletop $5 \mathrm{ml}$ or green-top $10 \mathrm{ml}$ vacutainer tubes for blood plasma and $10 \mathrm{ml} \mathrm{SST} \mathrm{Gold} \mathrm{BD} \mathrm{vacutainer} \mathrm{tubes} \mathrm{for}$ blood serum) and $1.5 \mathrm{ml}$ Eppendorf tubes. A total of $100 \mu \mathrm{l}$ of blood plasma, serum, or whole blood were pipetted into the sample well of the test kits, followed by application of assay diluent. Results were read $20 \mathrm{~min}$ later. For quality control, images of all test kits were uploaded to a cloud database via a portable, batteryoperated lateral flow assay reader/imager (Deki Reader, Fio Corporation, Toronto, Canada). The final determination of whether each assay was positive, negative, or invalid was based on visual inspection of the uploaded image.

We calculated the proportion of positive test results by sex and age group. We then used Fisher's exact test to compare prevalence rates by sex and Chi squared tests to compare prevalence rates by age group.

\section{Results}

The overall HBsAg prevalence among the 860 individuals tested was $13.7 \%(118 / 860)$ (Table 1). For males, the overall prevalence was $15.5 \%(51 / 330)$ and for females the overall prevalence was $12.6 \%(67 / 530)$. There were no statistically significant differences by $\operatorname{sex}(\mathrm{p}=0.24)$ or among the four age groups $(\mathrm{p}=0.99)$.

Table 1 HBsAg test results by age and sex

\begin{tabular}{|c|c|c|c|c|c|c|}
\hline \multirow[t]{2}{*}{ Age (years) } & \multicolumn{2}{|l|}{ Males } & \multicolumn{2}{|l|}{ Females } & \multicolumn{2}{|l|}{ Total } \\
\hline & Number tested & $\begin{array}{l}\text { Number (\%) } \\
\text { HBsAg+ }\end{array}$ & Number tested & $\begin{array}{l}\text { Number (\%) } \\
\text { HBsAg+ }\end{array}$ & Number tested & $\begin{array}{l}\text { Number (\%) } \\
\text { HBsAg+ }\end{array}$ \\
\hline $5-14$ & 37 & $6(16.2 \%)$ & 36 & $4(11.1 \%)$ & 73 & $10(13.7 \%)$ \\
\hline $15-29$ & 99 & $18(18.2 \%)$ & 215 & 25 (11.6\%) & 314 & $43(13.7 \%)$ \\
\hline $30-44$ & 80 & $10(12.5 \%)$ & 106 & 15 (14.2\%) & 186 & $25(13.4 \%)$ \\
\hline 45 and older & 114 & $17(14.9 \%)$ & 173 & $23(13.3 \%)$ & 287 & 40 (13.9\%) \\
\hline Total & 330 & $51(15.5 \%)$ & 530 & 67 (12.6\%) & 860 & $118(13.7 \%)$ \\
\hline
\end{tabular}




\section{Discussion}

Populations with HBsAg seroprevalence rates above $8 \%$ are considered to have a high burden of disease from hepatitis B [8]. The 14\% HBsAg seroprevalence rate found in this study for 2012-2013 is well above the $8 \%$ threshold. The risk of contracting hepatitis B was not correlated with gender, and the prevalence of chronic disease did not vary substantially by age in post-infant populations. The rate in this study from Bo, Sierra Leone, was lower than $21.4 \%$ prevalence found in a more recent, but smaller, study from another hospital in Bo [16]. However, the HBsAg rate reported here is similar to most recent studies from other countries in West Africa, where HBsAg rates reported in the past decade range from 11 to $15 \%$, including studies from Burkina Faso (14\%) [18], Ghana (13\%) [19], Mali (14\%) [20], Niger (15\%) [21], Nigeria (14\%) [22], and Togo (11\%) [23]. The similarity of these results to those from Bo reported here supports the validity of this study in addition to confirming that hepatitis B remains a substantial public health burden across West Africa.

The WHO guidelines for prevention and treatment of chronic hepatitis B infection issued in March 2015 promote several strategies for reducing the future burden from hepatitis $B$, including (1) vaccinating neonates and infants against hepatitis $B$ to prevent vertical transmission as well as provide protection from exposures later in life, (2) preventing mother-to-child transmission of HBV through use of antiviral therapy for pregnant women with chronic infection, and (3) taking steps to prevent the transmission of hepatitis B virus to susceptible individuals who may come into contact with the blood or body fluids of people with chronic HBV infections [24]. WHO recommends that almost all neonates receive a first dose of hepatitis B vaccine within the first $24 \mathrm{~h}$ after birth, with follow-up doses later in infancy [25]. Vaccination of newborns is especially important in places with high HBV endemicity levels [25].

Hepatitis B has been part of the national childhood vaccination schedule in Sierra Leone since 2009. About $83 \%$ of babies born in 2015 received three doses of the hepatitis $B$ vaccine [26]. Increasing this percentage will be critical for reducing the future burden of HBV in Sierra Leone. When the first dose is administered within a few hours after birth, the vaccine is more than $90 \%$ effective at preventing hepatitis B infection in infants whose mothers are HBsAg positive [25]. Given the high percentage of pregnant women in Sierra Leone who are chronic HBV carriers at risk of transmitting the virus to their neonates, having a vaccine rate below $100 \%$ means that many infants are still unnecessarily contracting HBV and being placed at risk of developing chronic infection that may cause serious health problems and premature death later in life. Additional preventable hepatitis $B$ disease may be caused by delays in the timing of the first vaccine dose, a challenge not fully captured in the statistics about 3-dose coverage. Antiviral treatment for the prevention of vertical transmission and the treatment of people who are seriously ill from chronic hepatitis B disease is generally not available in Sierra Leone at present. Opportunities to increase maternal access to these medications should be pursued by the Ministry of Health and Sanitation [27]. In the meanwhile, the limited availability of antiviral medications makes aggressive infant vaccination campaigns even more important.

\section{Limitations}

This study had several limitations. First, the inclusion criterion restricted participants to those who had fevers at the time of testing. This may cause the HBsAg prevalence rate to be overestimated. However, chronic HBV infection is unlikely to be a common cause of febrile illness, so we do not expect that the rate in the study population is considerably different than the rate in the general population. Second, we used a single type of test for HBV and the test kits did not distinguish between acute and chronic infections. However, the vast majority of adult infections in Sierra Leone are likely to be chronic infections that were acquired when the individuals were infants. The strengths of the study include the large sample size and the use of a test that has been shown to have high validity in other studies.

The high rate of chronic hepatitis $\mathrm{B}$ infection among adults and children in Bo makes it important to scale up the infant hepatitis $\mathrm{B}$ vaccination program in order to protect future generations from the burden associated with chronic liver disease.

\section{Abbreviations \\ DALY: disability-adjusted life year; GBD: Global Burden of Disease; HBsAg: hepatitis B surface antigen; HBV: hepatitis B virus; MH: Mercy Hospital; MHRL: Mercy Hospital Research Laboratory; RDT: rapid diagnostic test; SD: Standard Diagnostics; SDGs: Sustainable Development Goals; WHO: World Health Organization.}

\section{Authors' contributions}

$R A, K H J, T A L, C R T$, and DAS were involved in study conception. RA, JML, JL, UB, and ASB were involved in data collection. RA, DFD, KHJ, TAL, CRT, CY, and DAS were involved in data analyses. RA, KHJ, TAL, and CRT drafted the manuscript. All authors critically reviewed and accepted the final version of the manuscript. All authors read and approved the final manuscript.

\footnotetext{
Author details

${ }^{1}$ Mercy Hospital Research Laboratory, Kulanda Town, Bo, Sierra Leone. ${ }^{2}$ Department of Community Health and Clinical Studies, Njala University, Bo, Sierra Leone. ${ }^{3}$ Center for Biomolecular Science \& Engineering, U.S. Naval Research Laboratory, Washington, DC, USA. ${ }^{4}$ Department of Global \& Community Health, George Mason University, Fairfax, VA, USA. ${ }^{5}$ EDCTP, South African Office, Cape Town, South Africa.
} 


\section{Acknowledgements}

We acknowledge Prof. Russell Stothard of the Liverpool School of Tropical Medicine, Dr. Bockarie Kanneh of the Mercy Hospital, and laboratory technicians Jacob Buanie, Mohamed Biz Koroma, George Mbayo, Dinah B. Sondufu, and Vanessa Mereweather-Thompson.

\section{Competing interests}

The authors declare that they have no competing interests.

\section{Availability of data and materials}

The datasets used and/or analyzed during the current study are available from the corresponding author on reasonable request.

\section{Consent to publish}

Not applicable.

\section{Ethics approval and consent to participate}

Written informed consent was obtained from all adult study participants and from the parent or legal guardian of all children ( $<18$ years of age) who had not reached the legal age of maturity. All researchers who participated in data collection for this study completed training on human subjects protection through the Collaborative Institutional Training Initiative. The study was approved by the Sierra Leone Ethics and Scientific Review Committee as well as by the institutional review boards of Njala University (Bo, Sierra Leone), George Mason University (Fairfax, Virginia, USA, Protocol \#7909), the Liverpool School of Tropical Medicine (Liverpool, UK, Protocol \#11.79RS), and the U.S. Naval Research Laboratory (Washington, DC, USA, Protocol \#NRL.2012.0007).

\section{Funding}

This work was supported by the Joint Science and Technology Office, Defense Threat Reduction Agency (DTRA). The following distribution statement reflects the unclassified nature of the presented data: "Distribution statement A. Approved for public release; distribution is unlimited."

\section{Publisher's Note}

Springer Nature remains neutral with regard to jurisdictional claims in published maps and institutional affiliations.

\section{Received: 24 October 2017 Accepted: 1 February 2018}

Published online: 08 February 2018

\section{References}

1. Stanaway JD, Flaxman AD, Naghavi M, Fitzmaurice C, Vos T, Abubakar I, et al. The global burden of viral hepatitis from 1990 to 2013: findings from the Global Burden of Disease Study 2013. Lancet. 2016;388:1081-8. https ://doi.org/10.1016/S0140-6736(16)30579-7.

2. Lemoine M, Eholié S, Lacombe K. Reducing the neglected burden of viral hepatitis in Africa: strategies for a global approach. J Hepatol. 2015;62:469076. https://doi.org/10.1016/j.jhep.2014.10.008.

3. Lemoine M, Thursz M, Njie R, Dusheiko G. Forgotten, not neglected: viral hepatitis in resource-limited settings, recall for action. Liver Int. 2014;34:12-5. https://doi.org/10.1111/liv.12283.

4. WHO. Prevention \& control of viral hepatitis infection: a strategy for global action. Geneva: WHO; 2012.

5. WHO. Global health sector strategy on viral hepatitis 2016-2021. Geneva: WHO; 2016

6. UN. Transforming our world: the 2030 agenda for sustainable development. New York: UN; 2015

7. Lemoine M, Nayagam S, Thursz M. Viral hepatitis in resource-limited countries and access to antiviral therapies: current and future challenges. Future Virol. 2013;8:371-80. https://doi.org/10.2217/fvl.13.11.

8. Ott JJ, Stevens GA, Groeger J, Wiersma ST. Global epidemiology of hepatitis $B$ virus infection: new estimates of age-specific HBsAg seroprevalence and endemicity. Vaccine. 2012;30:2212-9. https://doi.org/10.1016/j.vacci ne.2011.12.116.

9. Schweitzer A, Horn J, Mikolajczyk RT, Krause G, Ott JJ. Estimations of worldwide prevalence of chronic hepatitis B virus infection: a systematic review of data published between 1965 and 2013. Lancet. 2015;386:1546-55. https://doi.org/10.1016/S0140-6736(15)61412-X.

10. Trépo C, Chan HLY, Lok A. Hepatitis B virus infection. Lancet. 2014;384:2053-63. https://doi.org/10.1016/S0140-6736(14)60220-8.

11. Locarnini S, Hatzakis A, Chen DS, Lok A. Strategies to control hepatitis B: public policy, epidemiology, vaccine and drugs. J Hepatol. 2015;62:S7686. https://doi.org/10.1016/j.jhep.2015.01.018.

12. Adesida SA, Tamba GF, Sahr F, Sahr GM. Seroprevalence of human immunodeficiency and hepatitis B viruses among patients at a health facility in Freetown, Sierra Leone. Sierra Leone J Biomed Res. 2010;2:28-31.

13. Wurie IM, Wurie AT, Gevao SM. Sero-prevalence of hepatitis B virus among middle to high socio-economic antenatal population in Sierra Leone. West Afr J Med. 2005;24:18-20.

14. Hodges M, Sanders E, Aitken C. Seroprevalence of hepatitis markers: HAV, HBV, HCV and HEV amongst primary school children in Freetown, Sierra Leone. West Afr J Med. 1998:17:36-7.

15. Torlesse $H$, Wurie IM, Hodges $M$. The use of immunochromatography test cards in the diagnosis of hepatitis B surface antigen among pregnant women in West Africa. Br J Biomed Sci. 1997;54:256-9.

16. Zoker EM, Sundufu AJ, Jacobsen KH. Seroprevalence of hepatitis B surface antigen in urban Bo, Sierra Leone. Trop J Med Res. 2017;20:41. https://doi. org/10.4103/1119-0388.198116.

17. Scheiblauer H, El-Nageh M, Diaz S, Nick S, Zeichhardt H, Grunert HP, et al. Performance evaluation of 70 hepatitis B virus (HBV) surface antigen ( $\mathrm{HBs} A g)$ assays from around the world by a geographically diverse panel with an array of HBV genotypes and HBsAg subtypes. Vox Sang. 2010;98:403-14. https://doi.org/10.1111/j.1423-0410.2009.01272.x.

18. Nagalo BM, Bisseye C, Sanou M, Kienou K, Nebié YK, Kiba A, et al. Seroprevalence and incidence of transfusion-transmitted infectious diseases among blood donors from regional blood transfusion centres in Burkina Faso, West Africa. Trop Med Int Health. 2012;17:247-53. https://doi.org/10 1111/j.1365-3156.2011.02902.x.

19. Candotti D, Danso K, Allain JP. Maternofetal transmission of hepatitis $B$ virus genotype E in Ghana, West Africa. J Gen Virol. 2007;88(Pt 10):268695. https://doi.org/10.1099/vir.0.83102-0.

20. Diarra A, Kouriba B, Baby M, Murphy E, Lefrere JJ. HIV, HCV, HBV and syphilis rate of positive donations among blood donations in Mali: lower rates among volunteer blood donors. Transfus Clin Biol. 2009;16:444-7. https:// doi.org/10.1016/j.tracli.2009.09.004.

21. Mayaki Z, Dardenne N, Kabo R, Moutschen M, Sondag D, Albert A, et al. Seroprevalence of infectious markers among blood donors in Niamey (Niger). Rev Epidemiol Sante Publique. 2013;61:233-40. https://doi. org/10.1016/j.respe.2012.12.018.

22. Musa BM, Bussell S, Borodo MM, Samaila AA, Femi OL. Prevalence of hepatitis B virus infection in Nigeria, 2000-2013: a systematic review and meta-analysis. Niger J Clin Pract. 2015;18:163-72. https://doi. org/10.4103/1119-3077.151035.

23. Agbenu E, Banla A, Kolou M, D'Almeida A, Kpotsra A, Dorkenoo A, et al. Serologic markers used for hepatitis B surveillance in Togo: status report and action proposals. Med Trop. 2008;68:621-4.

24. WHO. Guidelines for the prevention, care and treatment of persons with chronic hepatitis B infection. Geneva: WHO; 2015.

25. WHO. Hepatitis B vaccines. Wkly Epidemiol Rec. 2009;84:405-20.

26. UNICEF. State of the world's children. New York: UNICEF; 2016

27. Andersson MI, Rajbhandari R, Kew MC, Vento S, Preiser W, Hoepelman AIM , et al. Mother-to-child transmission of hepatitis B virus in sub-Saharan Africa: time to act. Lancet Glob Health. 2015;3:e358-9. https://doi. org/10.1016/S2214-109X(15)00056-X. 